\title{
Control of molecular weight in Ni(II)-catalyzed polymerization via the reaction medium
}

\author{
Damien Guironnet, Thomas Rünzi, Inigo Göttker-Schnetmann and Stefan Mecking*
}

The reaction medium controls polymerization with highly active $\left(\kappa^{2}-P, O\right)$-phosphinesulfonato nickel methyl complexes to afford polyethylenes ranging from low molecular weight $\left(M_{n}\right)$ branched material to high molecular weight $\left(M_{n}\right)$ strictly linear polymer.

Olefin polymerization by cationic complexes of $\mathrm{d}^{8}$ metals (late transition metals) have been studied intensely in the last decade. ${ }^{1}$ Due to their functional group tolerance, ethylene and 1-olefins can be copolymerized with polar monomers such as acrylates. ${ }^{2}$ Substantial and unique branching patterns can be introduced in ethylene homopolymerization. ${ }^{3}$ These studies prompted renewed interest in neutral nickel(II) ethylene polymerization catalysts. ${ }^{4,5}$ For example, by comparison to their cationic $\mathrm{Ni}$ (II) counterparts, they are more tolerant towards protic reagents such as water. ${ }^{6}$

In general, late transition metal alkyl complexes are prone to $\beta$-hydride elimination. This promotes chain transfer in catalytic olefin oligomerization and polymerization. In the development of late transition metal polymerization catalysts, substantial effort has been devoted to designing catalysts such that chain transfer is prevailed by chain growth in order to form high molecular weight polymer rather than oligomers or dimers, e.g. by appropriate steric shielding of the metal center. ${ }^{4}$ We report on a remarkable effect on polymer molecular weight and microstructure for a given catalyst simply by choice of the reaction medium (for a brief notation that with $\mathrm{Ni}(\mathrm{II})$ phosphinoenolato complexes higher molecular weight product is obtained in hexane vs. ethylene oligomerization in toluene as a solvent $c f$. ref. $5 a$ ).

Neutral $\mathrm{P}^{\wedge} \mathrm{O}$-chelated $\mathrm{Pd}(\mathrm{II})$ phosphinosulfonato complexes are versatile functional group-tolerant olefin polymerization catalysts. $^{7,8}$ Analogous Ni(II) complexes 1 [( $\left.\left.\mathrm{P}^{\wedge} \mathrm{O}\right) \mathrm{NiPh}\left(\mathrm{PPh}_{3}\right)\right]$ $\left(\mathrm{P}^{\wedge} \mathrm{O}=\mathrm{Ar}_{2} \mathrm{P}-\mathrm{C}_{6} \mathrm{H}_{4}-\mathrm{SO}_{3}\right)$ were found to polymerize ethylene to low molecular weight material $\left(M_{\mathrm{w}}=10^{3}\right.$ to $\left.4 \times 10^{3} \mathrm{~g} \mathrm{~mol}^{-1}\right)$ with an activity up to $5 \times 10^{4} \mathrm{TO} \mathrm{h}^{-1}$ upon activation with a scavenger for $\mathrm{PPh}_{3} .{ }^{9}$ Our interest in neutral Ni(II) phosphinosulfonate complexes evolved from studies of catalytic polymerization in dense $\mathrm{CO}_{2}{ }^{10}$

Chair of Chemical Materials Science, Dept. of Chemistry, University of Konstanz, 78464 Konstanz, Germany.

E-mail: stefan.mecking@uni-konstanz.de; Fax: + 497531 88-5152; Tel: + $49753188-5151$
Reaction of the phosphinesulfonic acid 2 with [(tmeda)$\left.\mathrm{NiMe}_{2}\right]$ (tmeda $=N, N, N^{\prime}, N^{\prime}$-tetramethylethylene diamine) at $-30{ }^{\circ} \mathrm{C}$ in $\mathrm{THF}$ resulted in expulsion of one $\mathrm{Ni}-\mathrm{Me}$ group as methane, and precipitation of $\mathbf{3}$ in quantitative yield (Scheme 1). ${ }^{1} \mathrm{H}$ NMR spectra of 3 in dmso- $d_{6}$ indicate a $2: 1$ ratio of Ni-bound methyl groups to tmeda thus confirming the dinuclear structure of $\mathbf{3}$ depicted.

The reaction of $\mathbf{2}$ with [(tmeda) $\mathrm{NiMe}_{2}$ ] in the presence of an excess of pyridine afforded the mononuclear pyridine complex 4 in high yield (Scheme 1). $\ddagger$ Crystals suitable for X-ray diffraction analysis were grown from dichloromethane solution. The solid state structure of $\mathbf{4}$ exhibits a square planar coordination geometry around the nickel center, the methyl ligand being cis to the phosphine (Fig. 1) $\ddagger$ This isomer appears to prevail also in solution exclusively. A single resonance is observed for the $\mathrm{Ni}-\mathrm{CH}_{3}$ moiety in ${ }^{1} \mathrm{H} \mathrm{NMR}$ spectra (doublet, ${ }^{3} J_{\mathrm{PH}}=7.6 \mathrm{~Hz}$ ).

The polymerization of ethylene with $\mathbf{3}$ and $\mathbf{4}$ was studied (Table 1). The complexes are highly active single site catalysts for the polymerization of ethylene. In toluene they convert ethylene to low molecular weight moderately branched polyethylene (with 10-18 methyl branches per 1000 carbon atoms). Activities exceed those reported for $\mathbf{1} /$ phosphine scavenger by an order of magnitude, in the absence of any scavenger (entries $1-1$ and 1-13). The observed (1.5-4.5) $\times 10^{5} \mathrm{TO}^{-1}$ are among the highest activities reported for neutral late transition metal catalysts. $^{4 c, i, n}$ The catalyst derived from $\mathbf{3}$ or $\mathbf{4}$ is compatible with potentially coordinating solvents, e.g. THF and supercritical $\mathrm{CO}_{2}$. Like in toluene, low molecular weight moderately branched materials were obtained.
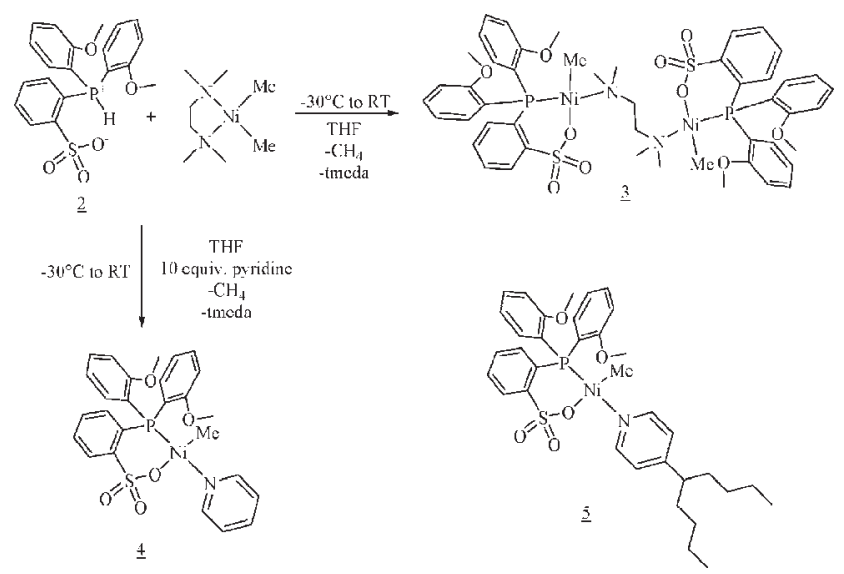

Scheme 1 


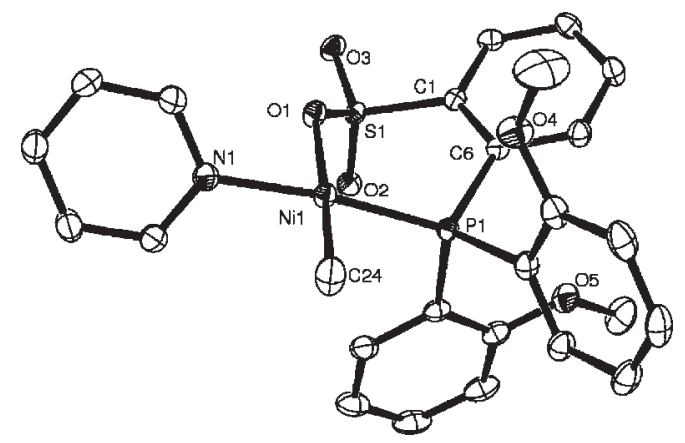

Fig. 1 Molecular structure of 4. Ellipsoids are shown with $50 \%$ probability. Hydrogen atoms are omitted for clarity.

Surprisingly, polymerization in heptane as a reaction medium afforded strictly linear high molecular weight polyethylene. Number average molecular weights exceed $10^{5} \mathrm{~g} \mathrm{~mol}^{-1}$ (Table 1), even at high polymerization temperatures which usually favor $\beta$-hydride transfer (entry 1-11 and Fig. 2). At $90{ }^{\circ} \mathrm{C}$ in heptane, the catalyst is stable for hours during polymerization (entries 1-10 and 1-11, also confirmed

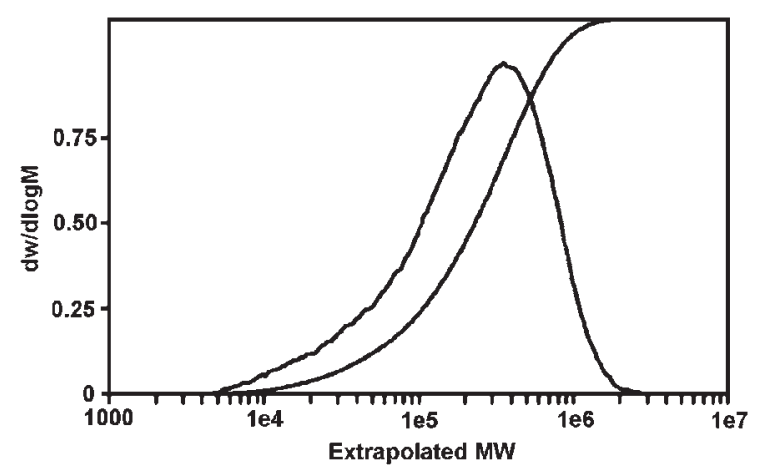

Fig. 2 GPC trace of polyethylene (entry 1-6). by following the ethylene uptake over time with a mass flow meter). Unfortunately, GPC analysis of a number of samples was hampered by a strong pressure increase on the columns, indicative of very high molecular weight fractions. However, NMR analysis confirms a high $M_{\mathrm{n}}$ of these samples, and no endgroups are observable (Table 1).

Coordinating solvents can promote chain transfer. ${ }^{11}$ For $\mathrm{THF}$, toluene and $\mathrm{scCO}_{2} \pi$ - or $\sigma$-donor coordination to the $\mathrm{Ni}(\mathrm{II})$ center may be possible. However, polymerization in methyl cyclohexane which is devoid of any donor functionality proceeds with similar activities as in toluene and likewise results in low molecular weight polyethylene (entry 1-13). Also, polymerization in the potentially $\pi$-donating 1 -octene affords high molecular weight polyethylene with activities comparable to those in heptane (entry 1-9). Remarkably, not even traces of 1-octene are incorporated within the experimental accuracy of ${ }^{13} \mathrm{C} N M R$ analysis. A comparison of the polymerization experiments in the aforementioned hydrocarbons also reveals no correlation of polymer molecular weights observed with the Flory-Huggins parameters of the polymer and respective solvent. ${ }^{12}$

Phenomenologically, the polymerization behaviour appears to correlate with the solubility of the catalyst precursor in the reaction medium, at the concentrations employed for polymerization studies. Insolubility (heptane, 1-octene) correlates with formation of linear high molecular weight polymer. This working hypothesis is underlined by polymerization with $\mathbf{5}$, an analogue of $\mathbf{4}$ which however is soluble in heptane due to the nonyl substituent on the pyridine ligand. Low molecular weight branched polymer is formed with very high activities (entry 1-17). Polymerization results in heptane-toluene solvent mixtures strongly depend on the ratio of the solvents (entries 1-15 and 1-16). This also underlines that the polymer molecular weight and microstructure formed rather correlates with solvent properties than the chemical nature or mere presence or absence of a solvent. A tentative explanation for these findings is a multinuclear nature of the catalyst formed from

Table 1 Polymerization results ${ }^{a}$

\begin{tabular}{|c|c|c|c|c|c|c|c|c|c|c|c|c|c|c|}
\hline Entry & Cat. & $\begin{array}{l}\mathrm{Ni} / \\
\mu \mathrm{mol}\end{array}$ & Solvent & $\begin{array}{l}P / \\
\text { bar }\end{array}$ & $\begin{array}{l}T / \\
{ }^{\circ} \mathrm{C}\end{array}$ & $\begin{array}{l}t / \\
\min \end{array}$ & $\begin{array}{l}\text { Av. TOF/ } \\
\text { mol }\left(\mathrm{C}_{2} \mathrm{H}_{4}\right) \\
\mathrm{mol}(\mathrm{Ni})^{-1} \mathrm{~h}^{-1}\end{array}$ & $\begin{array}{l}\text { Polymer } \\
\text { yield/g }\end{array}$ & $\begin{array}{l}10^{-3} M_{\mathrm{n}}{ }^{b} \\
(\mathrm{GPC}) / \\
\mathrm{g} \mathrm{mol}^{-1}\end{array}$ & $M_{\mathrm{w}} / M_{\mathrm{n}}^{b}$ & $\begin{array}{l}10^{-3} M_{\mathrm{n}}{ }^{c} \\
(\mathrm{NMR}) / \\
\mathrm{g} \mathrm{mol}^{-1}\end{array}$ & $\begin{array}{l}T_{\mathrm{m}} /{ }^{d} \\
{ }^{\circ} \mathrm{C}\end{array}$ & $\begin{array}{l}\text { Cryst. }{ }^{d} \\
(\mathrm{~mol} \%)\end{array}$ & $\begin{array}{l}\text { Branches }{ }^{e} \\
\text { x1000 C }\end{array}$ \\
\hline $1-1$ & 3 & 5 & Toluene & 40 & 60 & 30 & $3.5 \times 10^{5}$ & 24.8 & $(0.5)$ & $(1.8)$ & 0.8 & & & 15 \\
\hline $1-2$ & 3 & 5 & $\mathrm{H}_{3} \mathrm{CC}_{6} \mathrm{H}_{11}$ & 40 & 60 & 30 & $2.0 \times 10^{5}$ & 14.3 & $(0.8)$ & (1.7) & 0.8 & & & 16 \\
\hline $1-3^{f}$ & 3 & 10 & $\mathrm{scCO}_{2}$ & $f$ & 50 & 30 & $3.7 \times 10^{3}$ & 0.52 & n.d. ${ }^{h}$ & n.d. ${ }^{h}$ & 1.8 & 127 & 56 & 7 \\
\hline $1-4$ & 3 & 10 & 1-Octene & 40 & 50 & 135 & $1.3 \times 10^{4}$ & 7.15 & n.d. ${ }^{h}$ & n.d. ${ }^{h}$ & $>15$ & 136 & 59 & $<1$ \\
\hline $1-5$ & 3 & 4 & Heptane & 40 & 90 & 60 & $2.2 \times 10^{3}$ & 0.25 & n.d. ${ }^{h}$ & n.d. ${ }^{h}$ & $>15$ & 135 & 68 & $<1$ \\
\hline $1-6$ & 4 & 9 & Heptane & 40 & 70 & 60 & $7.9 \times 10^{3}$ & 1.99 & 101 & 3.2 & $>15$ & 135 & 52 & $<1$ \\
\hline $1-7$ & 4 & 5 & Toluene & 40 & 70 & 60 & $1.5 \times 10^{5}$ & 21.4 & $(0.8)$ & (1.9) & 0.8 & & & 14 \\
\hline $1-8$ & 4 & 5 & Toluene & 40 & 90 & 30 & $1.3 \times 10^{5}$ & 9.06 & $(0.5)$ & (1.7) & 0.8 & & & 14 \\
\hline $1-9$ & 4 & 5 & 1-Octene & 40 & 90 & 30 & $5.9 \times 10^{3}$ & 0.41 & 71 & 11.3 & $>15$ & & & $<1$ \\
\hline $1-10$ & 4 & 9 & Heptane & 40 & 90 & 30 & $2.6 \times 10^{4}$ & 1.83 & n.d. ${ }^{h}$ & n.d. ${ }^{h}$ & $>15$ & & & $<1$ \\
\hline $1-11$ & 4 & 8 & Heptane & 40 & 90 & 160 & $1.9 \times 10^{4}$ & 12.0 & 184 & 4.0 & nd & 137 & 56 & n.d. \\
\hline $1-12$ & 4 & 8 & THF & 40 & 90 & 30 & $7.4 \times 10^{4}$ & 8.27 & $(0.6)$ & $(1.7)$ & 0.8 & 95 & - & 11 \\
\hline $1-13$ & 4 & 4.5 & $\mathrm{H}_{3} \mathrm{CC}_{6} \mathrm{H}_{11}$ & 40 & 90 & 10 & $4.5 \times 10^{5}$ & 9.41 & $(0.5)$ & (1.8) & 0.8 & 90 & - & 15 \\
\hline $1-15$ & 4 & 8 & $\mathrm{H} / \mathrm{T}^{g} 70 / 30$ & 40 & 90 & 12 & $1.1 \times 10^{5}$ & 4.78 & $(0.6)$ & (1.6) & 0.9 & 90 & - & 15 \\
\hline $1-16$ & 4 & 5 & $\mathrm{H} / \mathrm{T}^{g} 80 / 20$ & 40 & 90 & 60 & $1.9 \times 10^{4}$ & 2.61 & 135 & 2.9 & $>15$ & 138 & 56 & $<1$ \\
\hline $1-17$ & 5 & 8 & Heptane & 40 & 90 & 60 & $1.7 \times 10^{4}$ & 3.83 & $(0.4)$ & $(2.1)$ & 0.7 & & & 18 \\
\hline
\end{tabular}

${ }^{a}$ Polymerization performed in a $250 \mathrm{~mL}$ steel reactor. ${ }^{b}$ Determined by GPC, referenced to linear PE. ${ }^{c}$ Determined by ${ }^{1} \mathrm{H}$ NMR at $130{ }^{\circ} \mathrm{C}$. ${ }^{d}$ From DSC. ${ }^{e}$ From ${ }^{13} \mathrm{C}$ NMR at $130{ }^{\circ} \mathrm{C}$, methyl branches observed exclusively. ${ }^{f} 5 \mathrm{~g}$ of ethylene added to $45 \mathrm{~mL}$ of $\mathrm{CO}_{2}$ at $30 \mathrm{MPa}^{2}$ then compressed to $65 \mathrm{MPa} .{ }^{g}$ Heptane-toluene mixture (v/v). ${ }^{h}$ Analysis hampered by a strong pressure increase of the GPC columns, indicative of very high molecular weight fractions. 
heterogeneous precursor suspensions, by comparison to mononuclear active species formed from homogeneous catalyst precursor solutions.

Noteworthy, the catalytic activities of the complexes $\mathbf{3}$ and $\mathbf{4}$ are lower in heptane and 1-octene than in other solvents. While the catalyst formed from $\mathbf{4}$ is stable for hours during polymerization at $90{ }^{\circ} \mathrm{C}$ and 40 bar in heptane, it decomposes relatively rapidly in toluene under identical conditions. Considering these differences in activities and polymer microstructures and excluding any influence by solvent donor abilities, we assume that different catalytically active species are present in heptane and 1-octene as compared to, e.g. toluene, i.e. a highly active species present in toluene produces low molecular weight, moderately branched PE while a less active species present in heptane produces linear high molecular weight PE.

In conclusion, the $\mathrm{P}^{\wedge} \mathrm{O}$-chelated phosphinesulfonato $\mathrm{Ni}$ (II) methyl complexes 3-5 are single component precursors to highly active polymerization catalysts. Polymer molecular weight and microstructure depend strongly on the reaction medium employed. By appropriate choice very high molecular weight polyethylene can be obtained, with catalysts which otherwise afford low molecular weight material. This is also the first unambiguous demonstration of preparation of polyethylene with high $M_{\mathrm{n}}$ with neutral Ni(II) $\mathrm{P}^{\wedge} \mathrm{O}$-chelated catalysts. While a high $M_{\mathrm{w}}$ or $M_{\mathrm{v}}$ was determined in some cases previously, as far as reported $M_{\mathrm{n}}$ was $\leq 10^{4} \mathrm{~g} \mathrm{~mol}^{-1} \cdot 1 c, 5,13$ That is, the large majority of polymer chains were rather short, in contrast to the materials obtained in this work.

We thank Lars Bolk for GPC, DSC and viscosimetry measurement. Financial support by the BMBF (project 03X5505) is gratefully acknowledged. S. M. is indebted to the Fonds der Chemischen Industrie.

\section{Notes and references}

$\ddagger$ Crystal data for 4: $\mathrm{C}_{26} \mathrm{H}_{26} \mathrm{NNiO}_{5} \mathrm{PS}, M=554.22 \mathrm{~g} \mathrm{~mol}^{-1}$, monoclinic, space group $P 2_{1} / c$ (no. 14), $a=11.5750(7), b=13.8165(6)$, $c=16.0318(10) \AA, \beta=98.617(5)^{\circ}, V=2512.8(2) \AA^{3}, Z=4$, $D_{\mathrm{c}}=1.465 \mathrm{~g} \mathrm{~cm}^{-3}, \mu(\mathrm{Mo}-\mathrm{K} \alpha)=0.957 \mathrm{~cm}^{-1}, T=100 \mathrm{~K}$, pale yellow rhombus, STOE IPDS T2, reflections measured: 41727 , unique reflections: $6018, h \mathrm{kl}$-range: -15 to $15 ;-18$ to $17 ;-21$ to $21,2 \theta_{\max }=$ $55.99^{\circ}, F^{2}$ refinement, parameters: $327, R_{1}=0.0363$ for 5141 data $\left(F_{\mathrm{o}}>4 \sigma\left(F_{\mathrm{o}}\right), 0.0478\right.$ (all data), $w R^{2}=0.0753$ for 5141 data $\left(F_{\mathrm{o}}>4 \sigma\left(F_{\mathrm{o}}\right), 0.0801\right.$ (all data), $R_{\mathrm{int}}=0.0921, \mathrm{GOF}=1.102$.

1 (a) S. D. Ittel, L. K. Johnson and M. Brookhart, Chem. Rev., 2000, 100, 1169-1203; (b) V. C. Gibson and S. K. Spitzmesser, Chem. Rev., 2003, 103, 283-316; (c) S. Mecking, Angew. Chem., Int. Ed., 2001, 40, 534-540; (d) S. Mecking, Coord. Chem. Rev., 2000, 203, $325-351$.

2 (a) L. K. Johnson, S. Mecking and M. Brookhart, J. Am. Chem. Soc., 1996, 118, 267-268; (b) S. Mecking, L. K. Johnson, L. Wang and M. Brookhart, J. Am. Chem. Soc., 1998, 120, 888-899; (c) L. Johnson, L. Wang, S. McLain, A. Bennett, K. Dobbs, E. Hauptman, A. Ionkin, S. Ittel, K. Kunitsky, W. Marshall, E. McCord, C. Radzewich, A. Rinehart, K. J. Sweetman, Y. Wang, Z. Yin and M. Brookhart, ACS Symp. Ser., 2003, 857, 131-142.
3 (a) L. K. Johnson, M. C. Killian and M. Brookhart, J. Am. Chem. Soc., 1995, 117, 6414-6115; (b) Z. Guan, P. M. Cotts, E. F. McCord and S. J. McLain, Science, 1999, 283, 2059-2062. Also cf. V. M. Moehring and G. Fink, Angew. Chem., Int. Ed. Engl., 1985, 24, 1001-1003.

4 (a) C. Wang, S. Friedrich, T. R. Younkin, R. T. Li, R. H. Grubbs, D. A. Bansleben and M. W. Day, Organometallics, 1998, 17, 3149-3151; (b) L. K. Johnson, A. M. A. Bennett, S. D. Ittel, L. Wang, A. Parthasarathy, E. Hauptman, R. D. Simpson, J. Feldman and E. B. Coughlin (DuPont), Int. Pat., WO98/30609, 1998; (c) T. R. Younkin, E. F. Connor, J. I. Henderson, S. K. Friedrich, R. H. Grubbs and D. A. Bansleben, Science, 2000, 287, 460-462; (d) F. A. Hicks and M. Brookhart, Organometallics, 2001, 20, 3217-3219; (e) R. Soula, J. P. Broyer, M. F. Llauro, A. Tomov, R. Spitz, J. Claverie, X. Drujon, J. Malinge and T. Saudemont, Macromolecules, 2001, 34, 2438-2442; (f) V. C. Gibson, A. Tomov, A. J. P. White and D. J. Williams, Chem. Commun., 2001, 719-720; (g) M. Zuideveld, P. Wehrmann, C. Röhr and S. Mecking, Angew. Chem., Int. Ed., 2004, 43, 869-873; (h) J. C. Jenkins and M. Brookhart, J. Am. Chem. Soc., 2004, 126, 5827-5842; (i) L. Zhang, M. Brookhart and P. S. White, Organometallics, 2006, 25, 1868-1874; (j) P. Kuhn, D. Sémeril, C. Jeunesse, D. Matt, M. Neuburger and A. Mota, Chem.-Eur. J., 2006, 12, 5210-5219; ( $k$ ) I. Göttker-Schnetmann, P. Wehrmann, C. Röhr and S. Mecking, Organometallics, 2007, 26, 2348-2362; (l) S.-M. Yu, A. Berkefeld, I. Göttker-Schnetmann, G. Müller and S. Mecking, Macromolecules, 2007, 40, 421-428; (m) A. Bastero, I. Göttker-Schnetmann, C. Röhr and S. Mecking, $A d v$. Synth. Catal., 2007, 349, 2307-2316; (n) P. Wehrmann and S. Mecking, Organometallics, 2008, 27, 1399-1408; (o) J. Pietsch, P. Braunstein and Y. Chauvin, New J. Chem., 1998, 467-472; (p) F. Speiser, P. Braunstein and L. Saussine, Acc. Chem. Res., 2005, 38, 784-793.

5 Early work: (a) W. Keim, F. H. Kowaldt, R. Goddard and C. Krüger, Angew. Chem., Int. Ed. Engl., 1978, 17, 466-467; (b) K. A. Ostoja-Starzewski and J. Witte, Angew. Chem., Int. Ed. Engl., 1987, 26, 63-64; (c) U. Klabunde and S. D. Ittel, J. Mol. Catal. A: Chem., 1987, 41, 123-134.

6 (a) A. Held, F. M. Bauers and S. Mecking, Chem. Commun., 2000, 301-302; (b) A. Tomov, J.-P. Broyer and R. Spitz, Macromol. Symp., 2000, 150, 53-58; (c) R. Soula, C. Novat, A. Tomov, R. Spitz, J. Claverie, X. Drujon, J. Malinge and T. Saudemont, Macromolecules, 2001, 34, 2022-2026; (d) I. Göttker-Schnetmann, B. Korthals and S. Mecking, J. Am. Chem. Soc., 2006, 128, 7708-7709; (e) S. Mecking, Colloid Polym. Sci., 2007, 285, 605-619.

7 (a) E. Drent, R. van Dijk, R. van Ginkel, B. van Oort and R. I. Pugh, Chem. Commun., 2002, 744-745; (b) T. Kochi, S. Noda, K. Yoshimura and K. Nozaki, J. Am. Chem. Soc., 2007, 129, 8948-8949; (c) S. Luo, J. Vela, G. R. Lief and R. F. Jordan, J. Am. Chem. Soc., 2007, 129, 8946-8947; (d) K. M. Skupov, P. R. Marella, M. Simard, G. P. A. Yap, N. Allen, D. Conner, B. L. Goodall and J. P. Claverie, Macromol. Rapid Commun., 2007, 28, 2033-2038.

8 A. Berkefeld and S. Mecking, Angew. Chem., Int. Ed., 2008, 47, 2538-2542.

9 R. J. Nowack, A. K. Hearley and B. Rieger, Z. Anorg. Allg. Chem., 2005, 631, 2775-2781.

10 (a) A. Bastero, G. Francio, W. Leitner and S. Mecking, Chem.-Eur. J., 2006, 12, 6110-6116; (b) D. Guironnet and S. Mecking, Polym. Prepr. (Am. Chem. Soc., Div. Polym. Chem.), 2008, 49, 450-451.

11 M. D. Doherty, S. Trudeau, P. S. White, J. P. Morken and M. Brookhart, Organometallics, 2007, 26, 1261-1269.

12 CRC Handbook of Polymer-Liquid Interaction Parameters and Solubility Parameters, ed. A. F. M. Barton, CRC press, Boca Raton, FL, 1990.

13 K. Kurtev and A. Tomov, J. Mol. Catal. A: Chem., 1994, 88, $141-150$. 